소아 방광요관역류에서 요관점막하 Polydimethylsiloxane (PDS) 주입술의 효과

\author{
전남대학교 의과대학 비뇨기과학교실 \\ 김선옥 · 주재상 · 임창민 · 오경진 · 정승일 · 강택원 · 권동득 - 박광성 · 류수방*

\section{Effect of Subureteral Injection of Polydimethylsiloxane (PDS) in Children with Vesicoureteral Reflux}

\author{
Sun-Ouck Kim, Jae-Sang Joo, Chang Min Im, Kyung-Jin Oh, Seung-II Jung, \\ Taek Won Kang, Dongdeuk Kwon, Kwangsung Park and Soo-Bang Ryu* \\ Department of Urology, Chonnam National University Medical School, Gwangiu, Korea
}

\begin{abstract}
Subureteral injection of bulking agents is an accepted, less invasive, treatment of vesicoureteral reflux (VUR) in children. We evaluated the efficacy of an endoscopic subureteral polydimethylsiloxane (Macroplastique ${ }^{\circledR}$ ) injection with primary VUR in children. A total of 21 patients (31 renal units), aged between 2 and 15 years were included in this study. The vesicoureteral reflux was grade I in 5 , grade II in 7 , grade III in 9, grade IV in 7 and grade V in 3 renal units. PDS was injected submucosally under the ureteric orifice, converting the opening to allow the elevation of the mucosa, so that the orifices lay on the summit of a small mound, which assumed an elevated crescent appearance by the end of the procedure. The patients were followed up from 6 to 24 months (mean 18.5 months) with voiding cystourethrography. Overall, the reflux was corrected in 26 of the renal units $(83.8 \%)$ in one injection. The correction rates, according to the reflux grade, were $100,100,88.8,71.4,66.7 \%$ for grades I to $\mathrm{V}$, respectively. There were no associated postoperative complications. The mean hospital stay and operation time were 2.7 days $(2 \sim 4$ days) and 17.5 minutes (12 25 minutes), respectively. In conclusion, for low grade reflux, subureteral PDS injection therapy could be a primary treatment for VUR in children because it is simple, less invasive, decreased hospital stay and showes a high success rate.
\end{abstract}

Keywords: Vesicoureteral reflux; Injection; Children

게재결정: 2008년 3월 17일

*교신저자: 류수방, 501-757, 전남대학교 의과대학 비뇨기과학교실, Phone: 062-220-6703, FAX: 062- 227-1643, E-mail: sbryu@chonnam.ac.kr

\section{서 론}

소아 방광요관역류의 요관점막하에 물질 주입을 통한 내 시경적 치료는 여러 연구에서 높은 성공률과 낮은 부작용을 나타내며 이전의 개복수술을 대신하여 사용되고 있다. ${ }^{1-4}$ 그러나 그 효과, 안전성 및 내구성에 대한 논란은 계속되고 

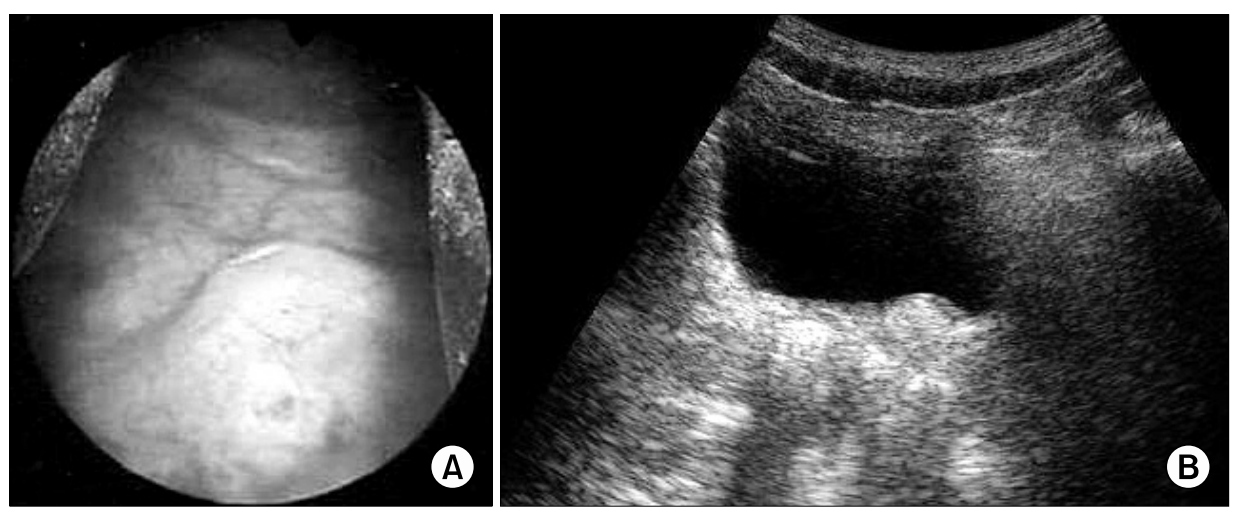

Fig. 1. Cystoscopic finding and ultrasonographic finding after subureteral injection therapy. (A) Ureteral oriffice after injection which shows inverted crescent shaped ureteral orifice at summit of mound. (B) Postoperative ultrasonography shows an echogenic nodule of injected polydimethylsiloxane (PDS).

있으며 아직은 요관점막하 물질 주입치료는 소아 역류 치료 의 표준적인, 일차적인 치료로는 받아들이지 못하고 있다. ${ }^{4}$ Macroplastique은 polydimethylsiloxane (PDS)이 운반체 인 polyvinylpyrroidone hydrogel 속에 부유하는 상태로 존 재하며 인체 내에서는 잘 분해되지 않고 탐식세포에 의해 탐식이 잘 되지 않아 원위부 이동의 위험이 적은 것이 특징 이다. ${ }^{5}$ 따라서 구미지역에서는 소아 역류의 요관점막하 주입 치료에 의해 70 90\%까지의 높은 성공률과 안전성을 보여 주었다. ${ }^{1,2}$ 국내의 연구 결과도 $80 \%$ 이상의 높은 성공률을 보여주고 있으나 3,4 아직 임상적인 효과와 안전성을 입증할 만한 충분한 연구 결과는 축적되지 못한 상황이다. 저자들은 소아에서 방광요관역류에 대한 PDS의 효과를 알아보고자 하였다.

\section{대상 및 방법}

2003년 1월부터 2007년 6월까지 내시경적 PDS 요관하 주입요법으로 방광요관역류를 치료한 후 추적이 가능했던 21명(남자 8명, 여자 13명)의 31역류 요관환자를 대상으로 이들의 의무기록지를 후향적으로 분석하였다. 대상 환자들 의 연령은 평균 5.5 세 $(2 \sim 15$ 세 $)$ 였고 평균 추적기간은 평군 18.5 개월(6 39개월)이었다. 모든 환자는 수술 전 복부초음 파와 배뇨중방광요도조영술, 요배양검사를 시행하였다. 수술 은 예방적 항생제 치료에도 요로계 감염이 있거나 추적관찰 중 방광요관역류가 더 심해지는 경우나 고등급의 역류에 수 술을 시행하였다. 역류 등급이 낮은 경우에도 부모가 약물 투여를 원하지 않고 수술을 원하는 경우에는 수술을 시행하 였다. 요관이 너무 적어 내시경이 들어가기 어려운 경우는 요도확장을 시행하였다. 시술은 수술실에서 전신마취 하에 이루어졌으며 소아는 9Fr. 굵기의 소아용 방광내시경을 이
용하였고, 4Fr. PDS 주입용 주사바늘을 이용하였다. 방광요 관역류가 있는 요관구의 6시 방향에 주입하였다. 시술 시 주사바늘을 방광점막에 2 3 mm 깊이로 찌른 후 뒤로 조 금씩 후퇴하면서, 요관구를 중심으로 주위가 고르게 화산모 양의 융기되어 요관구가 맞닿을 수 있도록 3 4회 정도 주 입하였고 주입량은 요관에 따라 차이가 있으나 $0.5 \sim 1.5 \mathrm{ml}$ 가 사용되었고 요관구가 넓은 horseshoe 형태나 stadium 형태를 보이는 환자는 비교적 많은 양을 주입하였다(Fig. 1A). 술 후 항생제는 요검사소견이 정상화될 때까지만 투여 하였다. 모든 환자들은 수술 1 주일 후에 신장 초음파를 시 행하여 요로 폐색이 있는지 확인하였고, 수술 3 개월 후에 배뇨중방광요도조영술과 방광 초음파를 시행하여 역류의 소 실 여부와 주입물질이 존재와 용적을 확인하였고 역류가 완 전히 소실되었을 경우에만 완치로 판정하였고 등급이 낮아 진 경우를 호전으로 판정하였다(Fig. 1B). 결과분석을 위한 통계는 SAS 프로그램을 이용하였고, $\mathrm{p}$ 값이 0.05 이하인 경 우를 유의하다고 판정하였다.

\section{결 과}

방광요관역류의 정도는 International grading system에 ${ }^{6}$ 의하여 grade I이 5요관, grade II가 7요관, grade III가 9요 관, grade IV가 7요관, grade $\mathrm{V}$ 가 3요관이었고, 일측성이 11 예(좌측 6예, 우측 5예), 양측성이 10 예였다. 평균수술 시 간은 약 17.5 (12 25)분이었으며, 평균입원 기간은 $2 \sim 4$ (2.7)일 이었다(Table 1).

전체 31 역류요관 중 26 요관(83.8\%), 21명의 환자 중 16 명(76.2\%)에서 역류가 소실되었다. 역류의 정도에 따른 시 술 결과는 grade I은 5요관 중 5요관, grade II는 7요관 중 7 요관, grade III은 9요관 중 8 요관, grade IV는 7 요관 중 5 
Table 1. Patient's characteristics

\begin{tabular}{lc}
\hline \multicolumn{1}{c}{ Variables } & Data (Mean) \\
\hline Age (years) & $2 \sim 15(5.5)$ \\
M/F ratio & $8: 13$ \\
VUR localization & \\
$\quad$ Right & 6 \\
Left & 5 \\
$\quad$ Bilateral & 10 \\
Operative time (minutes) & $12 \sim 25(17.5)$ \\
Hospitalization period (days) & $2 \sim 4(2.7)$ \\
Follw up duration (months) & $6 \sim 39(18.5)$ \\
\hline
\end{tabular}

$M$, male; $F$, female; VUR, vesicoureteral reflux

요관, grade $\mathrm{V}$ 는 3 요관 중 1 요관에서 역류가 소실되었다 (Table 2). grade I II의 저등급의 역류에서는 모든 환자 에서 시술 후 역류가 호전되었으며, grade III에서는 $88.8 \%$ 의 비교적 높은 성공률을 보였고, 고등급의 역류인 grade $\mathrm{IV} \sim \mathrm{V}$ 에서는 $60.0 \%$ 에서만 역류가 소실되었다(Table 3). 역류의 등급이 저등급에서 고등급으로 갈수록 성공률은 낮 아지는 양상을 보였으며 특히 grade $\mathrm{V}$ 는 $33.3 \%$ 로 매우 낮 은 성공률을 보였다. 중복요관은 2요관에서 grade III와 grade IV로 술전 검사에서 관찰되었으나 시술 후 grade III 는 역류가 소실되었으며 grade IV는 grade II로 등급이 낮 아진 소견이 관찰되었다. 시술 후 대부분의 환자에서 요로감 염이나 수술과 연관된 합병증은 보이지 않았다.

\section{고 찰}

방광요관역류 고정의 치료법으로 개복수술이 표준적인 치 료방법으로 생각되어왔으나 방광요관역류의 덜 침습적인 방 법으로 요관점막하 주입법이 개발되어왔다. 내시경적 주입 법은 최소 침습적이고 입원과 회복기간이 빠르다는 장점을 가지고 있으며 최근에는 입원을 하지 않고 시술후 바로 퇴 원하는 방법을 택하기도 한다. 방광요관역류에 대한 내시경 적 치료의 적용은 1981년 Matouschek에 의한 성인의 방광 요관치료의 적용이 처음으로 polytetrafluoroethylene (Teflon)을 이용하였으며 ${ }^{7} 1984$ 년 돼지를 이용한 동물 실험이후 소아 방광요관역류 치료에 적용하면서 상용화되어 사용되고 있다. ${ }^{8,9}$ 그러나, 내시경적 요관점막하 주입시술 자체는 안전 하고 비교적 효과적인 것으로 받아들여지고 있으나 주입물 질의 성질에 따라 여러 부작용들이 보고되고 있기 때문에 소아 역류에 대한 치료로 요관점막하 주입요법은 아직 진료
Table 2. Results of first polydimethylsiloxane (PDS) injection therapy

\begin{tabular}{|c|c|c|c|c|c|}
\hline \multirow{2}{*}{ Patient } & \multicolumn{2}{|c|}{ Pre-op. VUR grade } & \multicolumn{2}{|c|}{ Post-op. VUR grade } & \multirow{2}{*}{$\begin{array}{l}\text { Compli- } \\
\text { cations }\end{array}$} \\
\hline & Right & Left & Right & Left & \\
\hline 1 & I & $\|$ & - & - & \\
\hline 2 & III & - & - & - & \\
\hline 3 & - & IV & - & - & \\
\hline 4 & IV & $\|$ & III & - & \\
\hline 5 & $\|$ & $\|$ & - & - & \\
\hline 6 & III & IV & - & - & \\
\hline 7 & $\|$ & I & - & - & \\
\hline 8 & III & IV & - & - & \\
\hline 9 & $\|$ & I & - & - & \\
\hline 10 & III & - & - & - & \\
\hline 11 & - & $\|$ & - & - & \\
\hline 12 & - & III & - & $\|$ & \\
\hline 13 & $\|$ & - & - & & \\
\hline 14 & I & IV & - & - & \\
\hline 15 & V & IV & - & III & UTI \\
\hline 16 & III & 1 & - & - & \\
\hline 17 & - & IV & - & $\|$ & \\
\hline 18 & - & III & - & - & \\
\hline 19 & III & - & - & - & \\
\hline 20 & V & - & $\|$ & - & \\
\hline 21 & - & V & - & III & \\
\hline
\end{tabular}

VUR, vesicoureteral reflux; UTI, urinary tract infection

Table 3. Reflux correction accoding to grade

\begin{tabular}{lcccccc}
\hline Reflux grade & I & ॥ & III & IV & V & Total \\
\hline No. of refluxing unit & 5 & 7 & 9 & 7 & 3 & 31 \\
No. of corrected renal unit & 5 & 7 & 8 & 5 & 1 & 26 \\
\hline Resolution rate (\%) & 100 & 100 & 88.8 & 71.4 & 33.3 & 83.8
\end{tabular}

지침에 일차 치료법으로 권고되지는 못하고 있다. ${ }^{4}$ 내시경적 주입요법에서 주입물질에 대한 연구가 계속되고 있으며 주 입물질의 선택은 매우 중요하다. 주입물질은 효과를 나타내 기 위해 주입물질의 부피를 유지해야하며 흘러나오거나 타 장기로 이동하지 않아야한다. 또한 주입된 물질은 인체 내에 서 독성이 없어야하며, 생체 적합성이 있어야 하며 항원 반 응이 없어야한다. ${ }^{10}$

Teflon은 현재까지 가장 많이 사용되는 물질로 $90 \%$ 이상 높은 성공률을 보였으나 주입부위의 육아종 병변의 형성과 타장기로의 주입물질이 이동하는 부작용이 결점으로 제시되 면서 다른 물질인 collagen이 대체물질로 사용되었다. ${ }^{11,12}$ Collagen은 항원성이 적고 입자의 이동이나 주위장기로의 이동이 없으나 시간이 지남에 따라 주입물질이 용해되거나 흡수되어 그 부피가 줄어드는 단점이 있다. 또한 collagen 
주입후 전신성홍반성루푸스와 피부근육염 등의 결합조직질 환이 보고되었다. ${ }^{13}$ 1995년에 dextranomer microsphere와 hyaluronic acid로 구성된 dextranomer/hyaluronic acid copolymer (Deflux ${ }^{\circledR}, 80 \sim 120 \mu \mathrm{m}$ )를 주입물질로 사용하 였으며, Deflux는 생체내에서 자연 분해되는 성질이 있으며 미국 식품의약품국(FDA)의 공인을 받았으나 PDS에 비해 다소 낮은 성공률을 보이고 있다. ${ }^{14}$ Deflux는 체내에서 이동 이 잘 되지 않으면서도 면역반응을 일으키지 않으며 섬유모 세포를 증식시키고 콜라겐을 생성하여 주입 물질의 용적을 감소시키지 않는 좋은 조건을 갖는다. Polydimethylsiloxane (PDS, Macroplastique ${ }^{\circledR}$ )는 운반체인 (bio-excretable polyvinyl-pyrrolidone carrier hydrogel) 속에 부유하는 상 태로 존재하며 고형의 실리콘 탄성체로 이루어진 혼합 현탁 고형물로서 평균적으로 입자 크기가 커서 $209 \mu \mathrm{m}$ 이며 대식 세포에 탐식이 어렵게 때문에 주입부위에 크고 단단한 형태 로 자리 잡게 되어 다른 장기로의 이주 가능성이 낮다. ${ }^{11}$ 또 한, 구조적으로 인체 내에서 분해나 이동이 잘 되지 않고 염 증반응이 적으며 생체 적합성이 높아 1992년부터 방광요관 역류의 치료에 이용되고 있다. ${ }^{15}$ 본 연구에서 수술 후 3 개월 째 시행한 초음파 검사와 이후 추적 관찰한 초음파검사에서 역류교정을 위해 주입물질을 주입한 곳을 초음파로 관찰한 결과 주위 조직과 감별이 되는 주입물질이 주입된 부피를 잘 유지하여 지속적으로 관찰되었다.

$\mathrm{PDS}$ 는 방광요관역류에 대한 치료로서 안전하게 사용되 어 PDS의 주입 성공률은 70 90\% 정도로 높은 성공률을 보여왔다. Ozyavuz 등 ${ }^{16}$ 은 30 개의 역류요관에서 1 회 주입 시 26요관, 2회 주입 시 28요관에서 역류가 소실되었으며, 방광요관역류의 교정에 있어서 $\mathrm{PDS}$ 가 다른 물질보다 더 좋 은 결과를 보였다고 보고하였으며 Herz 등 ${ }^{17}$ 은 112 개의 역 류 요관에서 1회 주입으로 $81 \%$, 2회 주입 시에는 $90 \%$ 의 성공률을 보였다. Deflux와 비교한 연구결과로 Oswald 등 ${ }^{14}$ 는 PDS군에서 술후 3 개월 1 년에 $86.2 \%, 80.9 \%$ 의 성공률 을 보였으며 Deflux 군에서 각각 $71.4 \%, 67.6 \%$ 라고 보고 하여 PDS는 Deflux 보다 다소 치료 성공률이 높으나 장기 적으로는, 두 가지 물질 모두 용해성과 체내 흡수성 등으로 인하여 성공률이 저하되는 것으로 보인다. 이와는 반대되는 결과로 PDS를 사용한 유럽의 다기관 연구는 6년까지의 장 기추적관찰 결과 시간이 경과함에 따라 치료 성공률이 오히 려 개선됨을 관찰하였다. ${ }^{18}$

국내의 소아 방광요관역류에 대한 연구결과를 보면 Park 등은 총 19 역류요관 중 10 요관에서 역류가 소실되었으며
나머지 역류가 지속된 9개 요관 중 2요관은 추적관찰 중 자 연소실되었다고 하였으며 처음 역류가 소실되었던 10 요관중 2요관에서 grade I II의 재발이 있었다고 보고하였으며 시 술로 인한 부작용은 없었다고 하였다. 또한 Sung 등은 28 요관 중 21 요관이 완치되어 $75 \%$ 의 완치율을 보고하였으며 3 요관(10\%)에서 호전을 보여 모두 $85 \%$ 가 1차 치료에 성공 을 보였으며 2요관에서 추가 치료 없이 자연 완치되어 최종 적으로 23 요관(82\%)가 완치되었다고 보고하였다. 본 연구 에서 1 회 주입요법으로 $83.8 \%$ 의 높은 성공률로 이들의 보 고와 유사한 결과를 보였다. 내시경적 치료의 성공률은 역류 의 등급이 높을수록 낮아져 grade V에서는 $32 \%$, 단일요관 에서는 $77 \%$, 중복요관에서는 $58 \%$ 가 성공한다고 한다. ${ }^{19}$ 본 연구에서도 grade I II의 저등급의 역류에서는 모든 환자 에서 시술 후 역류가 호전되었으며, grade III에서는 $88.8 \%$ 의 비교적 높은 성공률을 보였고, 고등급의 역류인 grade IV V에서는 $60.0 \%$ 에서만 역류가 소실됨을 관찰하였다. Leonard 등 $^{20}$ 은 중복요관 6예의 전예에서 역류가 소실되었 다고 보고하였는데 본 연구에서 중복요관은 2 요관에서 관 찰되었으나 모두 역류가 소실되거나 호전됨을 관찰하였다.

요관점막하 주입법은 점막하 터널에 대한 방광근층의 지 지 부족을 보충하기 위해 요관구 아래에 지지구조를 만드는 것으로 방광이 충만 되면서 요관 점막이 서로 맞닿아 역류 를 막게된다. ${ }^{21}$ 내시경적 주입법의 기전으로 제안되는 것은 방광삼각부에 대한 요관의 강화된 고정력과 주입물질에 의 한 방광요관이행부의 개선된 지지기능, 주입물질에 의한 융 기로 인한 요관 내경의 감소를 들 수 있다. ${ }^{22}$ 실패율을 줄이 기 위해 정교한 술식이 요구되며 바늘을 방광점막하 2 3 $\mathrm{mm}$ 의 깊이로 요관구로부터 6시 방향에 주입하고 주입부위 의 왜곡을 방지하고 출혈을 감소시키기 위해서는 여러 군데 에 천자는 피하는 것이 좋다. ${ }^{14} \mathrm{PDS}$ 주입 후 실패한 예를 살펴보면, 수술후 주입 물질이 요관의 축을 벗어난 곳에 잘 못 위치해 있는 경우이거나 주입물질을 과량 주입하여 주입 물질을 덮고있는 점막의 미란을 야기하고 누출이 발생한 경 우가 그 원인이 될 수 있다. ${ }^{2,23}$ 저자들도 증예 수는 적었으 나 역류가 소실되지 않는 환자는 모두 추적 초음파에서 융 기가 소실되거나 약화된 소견을 보였다. Herz 등은 PDS 주입후 방광초음파검사에서 주입물질을 확인한 경우는 방광 요관역류 교정에 대한 높은 민감도와 특이도를 보인다고 하 였다. 초음파검사의 주입물질과 역류의 교정여부 간에 상호 관련성이 있다면 침습적인 배뇨방광요도조영술을 대신하여 수술후 추적검사로 초음파검사가 유용하게 사용될 수 있을 
것으로 생각된다.

방광요관역류에서 점막하 주입법은 그 술기의 간편하고 비침습적 술기로서 높은 성공률을 보여 임상가에게 수술적 치료 대상의 범위를 확대시키고 좀 더 적극적 치료를 고려 하게 하였다. 그러나 이전의 수술적 치료보다는 아직 재발율 이 높아 향후 재발을 줄이기 위한 노력이 계속되어야 할것 이며 치료의 안전성과 효과를 입증할 만한 대규모 연구와 지속적인 장기 추적관찰이 필요하다. 본 연구에서 내시경적 요관점막하 PDS 주입법은 전체 31역류요관 중 26요관에서 역류가 소실되고 $83.8 \%$ 의 성공률을 보여 1회 주입으로도 비교적 높은 성공률을 보였다. 그러나 grade $\mathrm{V}$ 의 고등급 방 광요관역류환자에서는 비교적 낮은 성공률이 보임으로서 아 직은 그 치료에 한계가 있는 것으로 보인다. 결론적으로 방 광요관역류의 치료로 내시경적 요관점막하 $\mathrm{PDS}$ 주입법의 결과는 grade $\mathrm{V}$ 를 제외한 방광요관역류에서 전통적인 개복 수술과 견줄만한 치료효과를 보일 뿐만 아니라 비침습적이 라는 측면에서 일차적인 치료로 개복수술을 대체할 수 있다 고 생각된다.

\section{References}

1. Dodat H, Valmalle AF, Weidmann JD, Collet F, Pelizzo G, Dubois R. Endoscopic treatment of vesicorenal reflux in children. Five-year assessment of the use of macroplastique. Prog Urol 1998;8:1001-6.

2. Herz D, Hafez A, Bagli D, Capolicchio G, McLorie G, Khoury A. Efficacy of endoscopic subureteral polydimethylsiloxane injection for treatment of vesicoureteral reflux in children: a north American clinical report. J Urol 2001;166:1880-6.

3. Park JW, Kim KS. An experience of endoscopic polydimethylsiloxane injection for the treatment of vesicoureteral reflux in children. Korean J Urol 2003;44:150-4.

4. Sung HH, Park HJ, Park KH. Experience of subureteral polydimethylsiloxane injection treatment in children with vesicoureteral reflux. Korean J Urol 2007;48:82-6.

5. Solomon LZ, Birch BR, Cooper AJ, Davies CL, Holmes SAV. Nonhomologous bioinjectable materials in urology: 'size matters'? BJU Int 2000;85:641-5.

6. Lebowitz RL, Olbing H, Parkkulainen KV, Smellie JM, TamminenMöbius TE. Internatinal system of radiolgraphic grading of vesicoureteral reflux. International reflux study in children. Pediatr Radiol 1985:15:105-9.

7. Matouschek E. Treatment of vesicorenal reflux by transurethral teflon- injection (author's transl). Urologe A 1981;20:263-4.

8. Puri P, O'Donnell B. Correction of experimentally produced vesicoureteric reflux in the piglet by intravesical injection of Teflon. Br Med J (Clin Res Ed) 1984;289:5-7.

9. O'Donnell B, Puri P. Treatment of vesicoureteric reflux by endoscopic injection of Teflon. Br Med J (Clin Res Ed) 1984;289:7-9.

10. Joyner BD, Atala A. Endoscopic substances for the treatment of vesicoureteral reflux. Urology 1997;50:489-94.

11. Bhatti HA, Khattak H, Boston VE. Efficacy and causes of failure of endoscopic subureteric injection of Teflon in the treatment of primary vesicoureteric reflux. Br J Urol 1993;71:221-5.

12. Smith DP, Kaplan WE, Oyasu R. Evaluation of polydimethylsiloxane as an alternative in the endoscopic treatment of vesicoureteral reflux. J Urol 1994;152:1221-4.

13. Cukier J, Beauchamp RA, Spindler JS, Spindler S, Lorenzo C, Trentham DE. Association between bovine collagen dermal implants and a dermatomyositis or a polymyositis-like syndrome. Ann Intern Med 1993;118:920-8.

14. Oswald J, Riccabona M, Lusuardi L, Bartsch G, Radmayr C. Prospective comparison and 1-year follow-up of a single endoscopic subureteral polydimethylsiloxane versus dextranomer/hyaluronic acid copolymer injection for treatment of vesicoureteral reflux in children. Urology 2002;60:894-7.

15. Park JW, Kim KS. An experience of endoscopic polydimethylsiloxane injection for the treatment of vesicoureteral reflux in children. Korean J Urol 2003;44:150-4.

16. Ozyavuz R, Ozgur GK, Yuzuncu AK. Subureteric polydimethylsiloxane injection in the treatment of vesico-ureteric reflux. Int Urol Nephrol 1998;30:123-6.

17. Herz D, Hafez A, Bagli D, Capolicchio G, McLorie G, Khoury A. Efficacy of endoscopic subureteral polydimethylsiloxane injection for treatment of vesicoureteral reflux in children: a North American clinical report. J Urol 2001;166:1880-6.

18. van Capelle JW, de Haan T, El Sayed W, Azmy A. The long-term outcome of the endoscopic subureteric implantation of polydimethylsiloxane for treating vesico-ureteric reflux in children: a retrospective analysis of the first 195 consecutive patients in two European centres. BJU Int 2004;94:1348-51.

19. Ortenberg J. Endoscopic treatment of vesicoureteral reflux in children. Urol Clin North Am 1998;25:151-6.

20. Leonard MP, Decter A, Mix LW, Johnson HW, Coleman GU. Endoscopic treatment of vesicoureteral reflux with collagen: preliminary report and cost analysis. $J$ Urol 1996;155:1716-20.

21. Gillenwater JY, Grayhack JT, Howards SS, Mitchell ME. Adult and pediatric urology. 4th ed. Philadelphia:Lippincott Williams \& Wilkins, 2002;2423-5, 2725-8.

22. Diamond DA, Caldamone AA, Bauer SB, Retik AB. Mechanisms of failure of endoscopic treatment of vesicoureteral reflux based on endoscopic anatomy. J Urol 2003;170:1556-8.

23. Vereecken RL, Proesmans W. Results of endoscopic treatment of vesico-ureteral reflux. Eur Urol 1995;27:76-9. 